\title{
Sinopse de Bauhinia sect. Pauletia (Cav.) DC. (Leguminosae: Caesalpinioideae: Cercideae) no Brasil $^{1}$
}

\author{
ANGELA MARIA S.F. VAZ ${ }^{2,4}$ e ANA MARIA G.A. TOZZI ${ }^{3}$
}

(recebido: 15 de abril de 2004; aceito: 14 de abril de 2005)

\begin{abstract}
Synopsis of Bauhinia sect. Pauletia (Cav.) DC. (Leguminosae: Caesalpinioideae: Cercideae) in Brazil). This treatment presents a key to identification, brief synonymy and taxonomic comments for nineteen taxa (eighteen species and one subspecies) of the genus Bauhinia sect. Pauletia, belonging to five series: Aculeatae, Acuminatae, Ariaria, Pentandrae and Perlebia. The distribution of the native species was plotted on three maps. Two plates, illustrative of Bauhinia aculeata and B. tarapotensis are presented.
\end{abstract}

Key words - Bauhinia, Brazil, Caesalpinioideae, Leguminosae, systematics

RESUMO - (Sinopse de Bauhinia sect. Pauletia (Cav.) DC. (Leguminosae: Caesalpinioideae: Cercideae) no Brasil). Este trabalho apresenta chave para identificação, sinonímia sumária e comentários sobre taxonomia para dezenove táxons (dezoito espécies e uma subespécie) do gênero Bauhinia sect. Pauletia pertencentes às séries Aculeatae, Acuminatae, Ariaria, Pentandrae e Perlebia. A distribuição das espécies nativas foi plotada em três mapas. Duas pranchas, ilustrativas de Bauhinia aculeata e de B. tarapotensis, são apresentadas.

Palavras-chave - Bauhinia, Brasil, Caeasalpinioideae, Leguminosae, sistemática

\section{Introdução}

Bauhinia L. é um gênero pantropical, com cerca de 300 espécies classificadas em 22 seções e 30 séries (Wunderlin et al. 1987), sendo que uma discussão sobre o seu histórico e a sua circunscrição pode ser encontrada em Fortunato (1986 [1987]) e Vaz (2001).

As espécies brasileiras de Bauhinia foram revisadas por Bentham (1870), onde figuram 64 espécies classificadas em três seções. Com o aumento progressivo das coleções, novas espécies foram descritas resultando em um total de mais de 200 nomes de espécies relativos ao gênero no Brasil (Vaz, inédito), que podem ser inseridos em cinco seções, conforme mencionado por Vaz \& Tozzi (2003b). Destas, a seção Caulotretus DC. (= sect. Tylotea Vogel) no Brasil foi revisada por Vaz (1979). A seção mais amplamente distribuída na região neotropical é Pauletia, que conta com cerca de 70

1. Parte da tese de doutorado de A.M.S.F. Vaz, Programa de Pós-Graduação em Biologia Vegetal, Unicamp.

2. Fundação Instituto Brasileiro de Geografia e Estatística, Diretoria de Geociências, Coordenadoria de Recursos Naturais, Avenida Chile 500/15 ${ }^{\circ}$ andar, 20031-170 Rio de Janeiro, RJ, Brasil.

3. Universidade Estadual de Campinas, Instituto de Biologia, Departamento de Botânica, Caixa Postal 6109, 13083-970 Campinas, SP, Brasil.

4. Autor para correspondência: avaz@jbrj.gov.br. espécies, das quais apenas duas paleotropicais (Wunderlin et al. 1987). No Brasil ocorrem 53 espécies de Bauhinia sect. Pauletia (Vaz 2001).

Bentham (1870) classificou as espécies de Bauhinia sect. Pauletia em três grupos informais, com base em caracteres das pétalas (forma), dos estames (número de estames férteis) e presença/ausência de acúleos. Wunderlin et al. (1987) estabeleceram, sob a seção Pauletia, cinco séries: Acuminatae, Ariaria, Cansenia, Pentandrae e Perlebia, acrescentando caracteres do pólen, porém não listaram as espécies a serem incluídas nas respectivas séries. Vaz \& Tozzi (2003a, b), adotaram a série Cansenia no sentido restrito e a desdobraram em uma nova série - Bauhinia ser. Aculeatae, enumerando as espécies ocorrentes no Brasil para ambas as séries. As séries Cansenia e Aculeatae correspondem ao primeiro e terceiro grupo informais de espécies de Bentham (1870).

Vaz \& Tozzi (2003b) apresentaram uma revisão de trinta e cinco espécies de Bauhinia sect. Pauletia ser. Cansenia.

O objetivo do presente trabalho é apresentar uma sinopse das cinco séries restantes de Bauhinia sect. Pauletia no Brasil.

\section{Material e métodos}

A partir de consulta à bibliografia especializada, as espécies de Bauhinia ocorrentes no Brasil foram classificadas quanto à seção e à série. De posse de uma 
listagem preliminar, os tipos das espécies de Bauhinia sect. Pauletia foram consultados e também diversas coleções de espécimes herborizados, procedentes dos seguintes herbários, cujas siglas estão de acordo com Holmgren et al. (1990): ASE, HCB, BHMH, BM, BOTU, C, CEN, CEPEC, CEUL, CGMS, CH, CPAP, CRI, CTES, CVRD, E, EAC, ESA, F, FACB, FUEL, GRAH, GUA, HAC, HB, HEPH, HISA, HRCB, HRB, HUEFS, HUFU, IAC, IAN, ISA, IBGE, INPA, IPA, JPB, K, MBM, MBML, MEXU, MG, MO, NY, OXF, OUPR, P, R, RB, RBR, RFA, RUSU, S, SI, SINU, SJRP, SP, SPF, SPFR, UB, UEC, UFG, ULM, US, VIC e W. Além disso, foram examinadas fotografias de tipos depositadas nos herbários A, B, F, K, LE, M, MA e NY. Procedeu-se, então, à revisão dos nomes de espécies de acordo com o Código Internacional de Nomenclatura Botânica (Greuter 2000). A lista de material examinado e o índice de coletores podem ser consultados em Vaz (2001) e serviram de base para a elaboração dos mapas de distribuição aqui apresentados. As citações no cabeçalho das espécies são referentes à obra original. As espécies foram numeradas de 36 a 53, visando dar continuidade ao tratamento de Bauhinia sect. Pauletia, que conta com a revisão de 35 espécies da série Cansenia (Vaz \& Tozzi 2003b).

\section{Resultados e Discussão}

Bauhinia sect. Pauletia (Cav.) DC., Prodr. 2:512. 1825 =Pauletia Cav., Icon. 5.5. 1799 - Lectótipo: Pauletia inermis Cav. [= B. ungulata L.], designado por De Wit (1956).

Os caracteres diagnósticos da seção Pauletia são os seguintes: árvores, arbustos ou subarbustos, às vezes flexuosos, porém nunca com gavinhas ou ramos espinescentes, acúleos presentes ou ausentes, botões e hipanto tubulosos, androceu com filetes conatos, formando uma coluna irregular, em geral, curta e internamente com apêndices ligulares presentes ou rudimentares; grãos de pólen, em geral, com sexina reticulada e com processos gemóides supratectais (Ferguson \& Pearce 1986, Gamerro \& Fortunato 2001, Vaz, 2001).

Distribuição: cerca de 70 espécies na America Tropical e 2 espécies sudeste da Ásia, sul da China e Malásia (Wunderlin et al. 1987). Brasil: 51 espécies nativas e 2 espécies cultivadas.

Chave para as séries de Bauhinia sect. Pauletia

1. Legume indeiscente; pétalas externamente lanosas, inclusive na unha VI. Bauhinia ser. Perlebia

1. Legume deiscente; pétalas nunca lanosas

2. Estames ante-sépalos férteis 5, alternados com 5 estames com anteras deficientes ou reduzidos a estaminódios filiformes V. Bauhinia ser. Pentandrae

2. Estames férteis 10, filetes com tamanhos desiguais, porém todos com anteras férteis

3. Inflorescências racemiformes, em geral com 7-15 flores; grão de pólen inaperturado; pétalas não ungüiculadas; valvas do fruto com margem ventral elevada II. Bauhinia ser. Acuminatae

3. Inflorescências fasciculiformes, com 2-6 flores ou compostas de pares sucessivos de flores geminadas em ramos folhosos, ou ainda um pseudo-racemo áfilo terminal; grão de pólen 3-6-aperturado; pétalas ungüiculadas; valvas do fruto com margem ventral não elevada

4. Plantas aculeadas; nectários extraflorais ausentes; pétalas oblanceoladas a obovado espatuladas; inflorescências parciais secundas, em ramos folhosos ...... III. Bauhinia ser. Aculeatae

4. Plantas inermes; nectários extraflorais intra-estipulares presentes, às vezes rudimentares; pétalas lineares a linear-lanceoladas, exceto em $B$. cheilantha e nesta, flabelado-venosas; inflorescências do tipo pseudo-racemo terminal áfilo

5. Estigma bilobado; legume lenhoso, obovóide, 2,5-3,8 cm de largura; grão de pólen porado, sexina com processos supratectais espinescentes IV. Bauhinia ser. Ariaria

5. Estigma clavado; legume coriáceo, contorno estreito-oblongo a linear, até $2,5-3 \mathrm{~cm}$ de largura; grão de pólen colporado ou colpado, sexina, em geral, com processos supratectais gemóides I. Bauhinia ser. Cansenia 
Sinopse das séries de Bauhinia sect. Pauletia

I. Bauhinia ser. Cansenia (Raf.) Wunderlin, K. Larsen \& S.S. Larsen, Biol. Skr. 28:12. 1987, p. parte. Tipo: Cansenia ungulata (L.) Raf. [=Bauhinia ungulata L.].

Distribuição: América Tropical (Wunderlin et al. 1987).

A descrição da série Cansenia e a revisão das espécies, listadas a seguir estão em Vaz \& Tozzi (2003b): 1. Bauhinia acuruana Moric., 2. B. aureopunctata Ducke, 3. B. bombaciflora Ducke, 4. B. brevipes Vogel, 5. B. burchellii Benth., 6. B. caloneura Malme, 7. B. campestris Malme, 8. B. candelabriformis R.S. Cowan, 9. B. cheilantha (Bong.) Steud., 10. B. cinnamomea DC. 11. B. conwayi Rusby, 12. B. cupulata Benth., 13. B. curvula Benth., 14. B. dubia G. Don, 15a. B. dumosa Benth. var. dumosa, 15b. B. dumosa var. viscidula (Harms) Vaz \& Marquete, 16. B. fusconervis (Bong.) Steud., 17. B. gardneri Benth., 18. B. goyazensis Harms, 19. B. grandifolia (Bong.) Steud., 20. B. holophylla (Bong.) Steud., 21. B. leptantha Malme, 22. B. longicuspis Benth., 23 B. longifolia (Bong.) Steud., 24 B. longipedicellata Ducke, 25. B. malacotricha Harms, 26. B. malacotrichoides R.S. Cowan, 27. B. membranacea Benth., 28. B. platyphylla Benth., 29. B. pulchella Benth., 30. B. rufa (Bong.) Steud., 31. B. smilacifolia Benth., 32. B. subclavata Benth., 33. B. tenella Benth., 34a. B. ungulata var. cuyabensis (Bong.) Vaz, 34b. B. ungulata var. obtusifolia (Ducke) Vaz, 34c. B. ungulata var. parvifolia (Ducke) Vaz, 34d. B. ungulata L. var. ungulata, 35. B. urocalyx Harms.

II. Bauhinia ser. Acuminatae Wunderlin, K. Larsen \& S.S. Larsen, Biol. Skr. 28:13. 1987. Tipo: Bauhinia acuminata $\mathrm{L}$.

Arvoretas ou arbustos. Ramos inermes. Nectários extraflorais subulados, ápice truncado, emergindo da parte lateral da estípula linear simétrica, 1-2 $\times$ ca. 0,5 mm. Folhas bilobadas, 4-10,5 × 4,3-10,5 cm. Inflorescência racemiforme unilateral, eixo no total 2-6 cm compr., 7-15-flora, bráctea foliácea ausente; botão floral fusiforme-cuspidado, nunca alado ou costado, ápice apendiculado, pré-antese ca. $3,5 \mathrm{~cm}$ de compr.; hipanto turbinado, internamente glabro; cálice na antese espatáceo, fenestrado na base; pétalas alargadas obovadas a lanceolado-obovadas, não unguiculadas, $4 \times 1,8 \mathrm{~cm}$, nunca lanosas externamente; 10 estames férteis, estaminódios ausentes, conatos na base formando coluna irregular, coluna até $3 \mathrm{~mm}$, internamente monadelfa com apêndice ligular obsoleto, viloso, externamente glabra a vilosa ou com tufos de pêlos concentrados na base dos estames alternipétalos; grãos de pólen inaperturados com processos supratectais gemóides (Larsen 1975, Vaz 2001); estipe 2 cm, livre, estigma bilobado. Legume com contorno oblongo, base acuminada, valvas $8-9,5 \times 2 \mathrm{~cm}$, internamente não divididas em compartimentos, externamente com margem ventral elevada; semente com apêndice unciforme encobrindo o hilo, com linhas em leque e foveoladas (Trivedi et al. 1980).

Distribuição: sudeste da Ásia, sul da China e Malásia (Wunderlin et al. 1987). Uma espécie cultivada no Brasil.

\section{Bauhinia acuminata L., Sp. Pl.: 375. 1753.}

Iconografia: De Wit (1956).

Arvoretas ou arbustos, nativas do sudoeste da Ásia (De Wit 1956). Espécie cultivada no Brasil.

III. Bauhinia ser. Aculeatae Vaz \& A.M.G.A. Azevedo, Novon 13:141. 2003. Tipo: Bauhinia aculeata L.

Arvoretas ou arbustos multicaules, como forma de resistência após o corte ou queimada, mas nunca subarbusto xilopodífero. Ramos com acúleos geminados, infra-estipulares, rígidos, dilatado-uncinados, ascendentes, recurvos ou incurvos, às vezes, um dos acúleos é menor ou deficiente, até ausente. Nectários extraflorais ausentes. Folhas inteiras a $2 / 3$ bilobadas, nunca bifolioladas, em geral, 3-15 × 1,9-10,5 cm. Inflorescência fasciculiforme, unilateral, 2-5(-6)-floras, eixo $0,4-1,5 \mathrm{~cm}$, bipartido a bifurcado a curtamente ramificado, flores geminadas a aglomeradas; bráctea foliácea ausente; botão floral tubuloso a tubulosofusiforme, ou ainda clavado (B. mollis), nunca alado, corniculado ou cuspidado, ápice às vezes cristado (= constrição subapical), pré-antese (3-)4,5-11,5 cm compr.; hipanto turbinado com contorno linear ou tubulososo a piriforme em $\mathrm{B}$. mollis, internamente glabro; cálice na antese espatáceo e fenestrado na base; pétalas alargado-oblanceoladas, lanceolado-espatuladas a obovado-espatuladas, estreitando-se em direção à base ungüiculada, $(2,5-) 4-11 \times 0,7-2,6 \mathrm{~cm}$, nunca lanosas externamente ou na unha; 10 estames férteis conatos na base, formando coluna irregular com 1-20 mm compr., coluna internamente monadelfa com apêndice ligular, livre ou adnata ao filete, externamente pubescente a hirsuta, com tufos de pêlos concentrados na base dos estames alternipétalos até glabra, estaminódios ausentes; grãos de pólen 5-colpados, às vezes 3-4 
colpados, colpos muito curtos, rasos ou irregulares em vista polar, com processos supratectais gemóides (Gamerro \& Fortunato 2001, Vaz 2001); estipe 0,8-6,5 cm, livre ou adnato em ca. de $1 / 6$ do comprimento total do hipanto, estigma bilobado. Legume com contorno estreitamente oblanceolado a linear, deiscência elástica, 6-31,5 × 1,1-3,5 cm, internamente não divididas em compartimentos, externamente sem margem ventral elevada; semente sem apêndice unciforme encobrindo o hilo, com linhas em leque e foveoladas (Beltrati \& Paoli 1989).

Distribuição: América tropical.

Chave para as espécies de Bauhinia ser. Aculeatae no Brasil

(Espécie cultivada marcada com *)

1. Botão com ápice clavado; hipanto tubuloso a piriforme; cálice fendido longitudinalmente em 2-3 lobos unidos no ápice ou subespatáceo e profundamente fenestrado na base; ramos, inflorescência e legume sórdido-tomentosos

44. B. mollis

1. Botão estreitando-se gradativamente em direção ao ápice; hipanto turbinado a linear; cálice espatáceo e fenestrado na base; ramos, inflorescência e legume ferrugíneo-tomentosos até glabros

2. Folhas inteiras, às vezes inteiras e com ápice bífido

3. Acúleos recurvados; folhas elípticas a ovado-oblongas, geralmente 5-11 ×2,5-3,8 cm; pétalas $5-5,5 \times 1,1 \mathrm{~cm}$ 43. B. integerrima

3. Acúleos em geral, ascendentes a retos; folhas largamente ovadas a ovado-lanceoladas, geralmente 6-10 × 4,3-6,5 cm; pétalas ca. $9 \times 0,8 \mathrm{~cm}$.

45. B. ovata

2. Folhas bilobadas com lobos foliares concrescidos em 1/3-4/5 do comprimento total

4. Botão floral na pré-antese ca. $11 \mathrm{~cm}$ compr.; pétalas geralmente $9-11 \times 1,6-2,6 \mathrm{~cm}$; legumes ca. $30-40 \times 2,2-3 \mathrm{~cm}$

5. Lobos foliares ovado-lanceolados, em geral concrescidos em ca. de $1 / 2$ do comprimento total 42. B. forficata

5. Lobos foliares ovado-oblongos, concrescidos em ca. de $2 / 3$ ou mais do comprimento total 37. B. acreana

4. Botão floral na pré-antese 4,5-7,5 cm compr.; pétalas 4,5-9 × 0,8-2,5 cm; legumes ca. 13-14 $\times 1,5-1,8 \mathrm{~cm}$

6. Folhas mais largas que longas; ovário e estipe glabros ou apenas com pêlos glandulosos

6. Folhas tão ou mais longas que largas; ovário e estipe tomentosos a glabrescentes 46. B. platypetala

7. Lobos foliares concrescidos em menos de $1 / 3$ do comprimento total 39. B. affinis

7. Lobos foliares concrescidos em ca. de $1 / 2$ a $2 / 3$ do comprimento total

8. Lobos foliares arredondados 38. B. aculeata*

8. Lobos foliares mais ou menos obtusos a agudos

9. Ramos retos ou flexuosos, cinéreos e glabrescentes 41. B. caatingae

9. Ramos em ziguezague, alvos e tomentosos..... 40. B. albicans

37. Bauhinia acreana Harms, Notizbl. Bot. Gard. Berlin 6:307. 1915. Tipo. BOLIVIA: "Gebiet des Rio Acre, Cobija”, I-1912 (fl.), Ule 9441 (holótipo B, destruído: fotografia RB! ex F negativo $n^{\circ} 1561$ ).

Iconografia: não há.

Árvores 4-5 m alt. ou arbustos 2-3 m alt., com distribuição no Peru e Brasil, Estados do Acre, Amazonas, Ceará, Mato Grosso, Rondônia e Pará (figura 3). Habita na floresta Amazônica, em formações de mata alta de terra firme, campo e em capoeiras.

Ducke $(1922,1950)$ fez uma breve descrição e citou localidades onde coletou B. acreana nos estados do Acre, Amazonas e Pará. Bauhinia acreana pertence ao complexo B. forficata, sendo considerada por alguns autores como um sinônimo desta. Difere, no entanto, pela forma das folhas, botões e flores mais robustos e frutos mais lenhosos.

38. Bauhinia aculeata L., Sp. Pl. ed. 1, p.374. 1753. Tipo: COLÔMBIA ou VENEZUELA, Herb. Clifford 156 (holótipo BM).

Figura 1. 


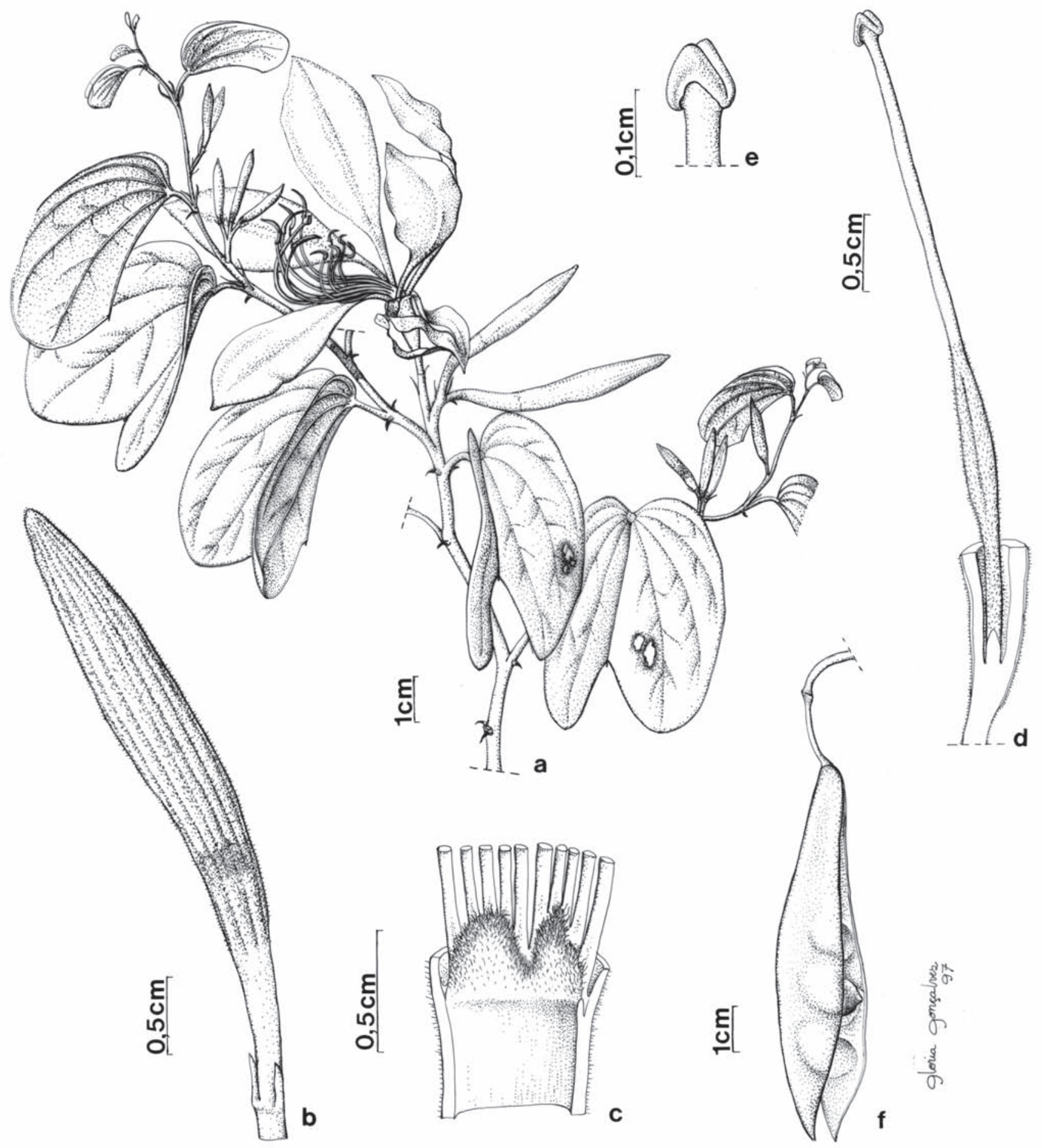

Figura 1. Bauhinia aculeata a. Ramo florífero com botões e flor com cálice espatáceo. b. Botão floral. c. Parte inferior dos filetes e coluna estaminal em continuidade com a face interna do hipanto. d. Gineceu inserido no hipanto seccionado. e. Detalhe do estigma bilobado. f. Legume. ( Vaz 1179).

Figure 1. Bauhinia aculeata a. Flowering branch with buds and flower with spathaceous calyx. b. Floral bud. c. Inferior portion of the filaments and staminal column in continuity with the internal face of the hypanthium. d. Gynoecium included in the sectioned hypanthium. e. Detail of the bilobed stigma. f. Legume. (Vaz 1179). 
Arvoretas ca. 7 m. alt., com distribuição na Bolívia, Cuba, Equador, El Salvador, Panamá, Peru e Venezuela, sendo cultivada no Brasil. Ver comentários sobre a taxonomia desta espécie adiante, sob B. affinis Vog.

39. Bauhinia affinis Vogel, Linnaea 10:594. 1838 (1836). = Pauletia affinis (Vogel) A. Schmitz, Bull. Jard. Bot. Nat. Belg. 43:388. 1973. Tipo: BRASIL: SAnTA Catarina: ano 1815 (fl.), Chamisso s.n. (holótipo B, destruído: fotografia RB! ex F negativo $n^{\circ} 1564$; lectótipo LE: fragmento BAB, designado por Fortunato 1996).

Iconografia: Fortunato (1996).

Arbustos, com distribuição na Argentina (Fortunato 1996) e Brasil, Estados do Rio de Janeiro, Paraná e Santa Catarina (figura 4). Habita na floresta Atlântica.

Bauhinia affinis pertence ao complexo Bauhinia aculeata. Wunderlin (1976) considerou B. affinis como sinônimo de Bauhinia aculeata, juntamente com inúmeros outros binômios, inclusive Bauhinia caatingae e B. albicans. Considerando-se que, de acordo com as coleções examinadas, as populações de $B$. affinis, $B$. caatingae, $B$. albicans e $B$. aculeata, estão em áreas geográficas não conectadas entre si, decidiu-se manter as espécies citadas como distintas, com base nos caracteres foliares e dos ramos.

40. Bauhinia albicans Vogel, Linnaea 13:304. 1839. Tipo: BRASIL: RIO DE JANEIRO: Entre Rio de Janeiro e Campos, s.d., Sellow 201 (holótipo B, destruído: fotografia RB! ex F negativo $n^{\circ} 1565$; isótipos não localizados).

Iconografia: não há.

Arbustos muito ramificados 1-3 m alt., com distribuição no Brasil, estado do Rio de Janeiro (figura 4). Habita na floresta baixa e seca com cactáceas, sobre solo arenoso-argiloso e em ambientes mais secos, na beira de estradas na região litorânea do norte-fluminense. Ver discussão sobre a taxonomia sob B. affinis.

41. Bauhinia caatingae Harms in Engl., Bot. Jahrb. Syst. 42:209. 1908. Tipo: BRASIL: BAHIA: Tamburi, X-1906 (bt./fl.), Ule 7277 (holótipo B, destruído: fotografia RB! ex F negativo $\left.n^{\circ} 1571\right)$.

Iconografia: não há.

Árvores 2,5-5 m alt. ou arbustos 1-2 m alt. (Vaz 2003), com distribuição no Brasil, estados da Bahia, Ceará, Goiás e Minas Gerais (figura 4). Habita na Caatinga, em carrasco seco com solo argiloso; floresta decidual, com solo calcário; transição cerrado-caatinga, afloramento de calcário e áreas de pastagem abandonadas na região da caatinga.

O epíteto específico escolhido pelo autor da espécie na grafia original era "catingae", o qual deve ser corrigido, pois o mesmo é uma referência ao tipo de vegetação de Caatinga, no local da coleta. Ver comentários sobre a taxonomia sob B. affinis.

42. Bauhinia forficata Link, Enum. Hort. Berol. 1:404. 1821. $\equiv$ Pauletia forficata (Link) A. Schmitz, Bull. Jard. Bot. Nat. Belg. 43: 389. 1973. Tipo: "Hab. in Brasilia" (holótipo não localizado).

= Bauhinia aculeata Vell., Fl. Flum. 171. 1829; Arch. Mus. Nac. Rio de Janeiro 5:171.1881 (non L., 1753; nec Cav. 1799). Tipo: Icones 4: tábula 83. 1831 (lectótipo designado por Lima 1995).

= Pauletia longiflora Bong., Mém. Acad. Imp. Sci. Saint-Pétersbourg, sér. 6, Sci. Math. seconde Pt. Sci. Nat. 4:128. 1838. $\equiv$ Bauhinia longiflora (Bong.) Steud., Nom. Bot. ed. 2, 191, sphalm. 291. 1840. 三 Bauhinia forficata var. longiflora (Bong.) Benth., in Mart., Fl. Bras. 15(2):201. t. 50. 1870. $\equiv$ Pauletia forficata var. longiflora (D.Dietr) A. Schmitz, Bull. Jard. Bot. Nat. Belg. 43:389. 1973. Tipo: BRASIL: Rio DE JANEIRo, Bongard s.n. (holótipo LE).

= Bauhinia brasiliensis Vogel, Linnaea 13:302.1839. Tipo. BRASIL: Rio DE JANEIRO: Sellow s.n. (síntipo não localizado); Monte Corcovado, Luschnath s.n. (síntipo $\mathrm{LE}$, fragmento e fotografia $\mathrm{BAB}$ ).

= Bauhinia breviloba Benth., in Mart., Fl. Bras. 15(2):197. 1870. Tipo: BRASIL: Divisa do RIO DE JANEIRO com Espírito SAnto, Rio Itabapoana, s.d., Principe Maximilianus Neovidensis s.n. (síntipo não localizado). BAHIA: Serra Jacobina, s.d., Blanchet 3293 (isossíntipo $\mathrm{B}$, destruído: fotografia RB! ex $\mathrm{F}$ negativo $\mathrm{n}^{\circ} 1570$; isossíntipo OXF!: fotografia RB!). Piaú, s.d., Gardner 1937 (isossíntipo OXF!: fotografia RB!).

= Bauhinia forficata var. latifolia Benth., in Mart., Fl. Bras: 15(2):201. $\equiv$ Pauletia forficata var. latifolia (Benth.) A. Schmitz, Bull. Jard. Bot. Nat. Belg. 43:389. Tipo: BRASIL: São PaUlo: Amparo, V-1857 (fl.), G.A. Lindberg 403 (holótipo S!: fotografia RB!).

Bentham (1870) descreveu B. breviloba dando ênfase ao grau de bipartição da folha, que possui lobos concrescidos em cerca de 3/4 do comprimento total e, citando-a como próxima de B. tarapotensis. Esta última, no entanto, é distinta e pertencente à ser. Ariaria (ver adiante).

Os sinônimos citados acima sob B. forficata coincidem com os citados por Fortunato (1996). Esta autora (1986) distinguiu uma subespécie, com base nos caracteres reproduzidos na chave a seguir. 
1. Botão floral com ápice agudo; coluna estaminal pubescente, às vezes, glabra; folha cartácea, truncada ou arredondada na base..... subsp. forficata

1. Botão floral com espessamento na região apical; coluna estaminal glabra; folha subcoriácea; arredondada a cordada na base. subsp. pruinosa

\section{2a. Bauhinia forficata Link subsp. forficata}

Iconografia: Bentham (1870); Lorenzi (1992 fotografias do hábito, ramos com flores, fruto, semente, casca e madeira); Vaz \& Silva (1995).

Árvores 13-15 m alt., arvoretas, em geral, 5-7 m alt. ou arbustos com distribuição no Brasil, Estados de Alagoas, Bahia, Espírito Santo, Minas Gerais, Paraná, Pernambuco, Piauí (somente uma coleta: Gardner 1937), Rio de Janeiro, Santa Catarina e São Paulo. (figura 3). Habita nas encostas de floresta Atlântica, na floresta higrófila no sul da Bahia e na floresta de tabuleiro no Espírito Santo. Em vegetação secundária (capoeira), beira de estrada, pastos e plantação de cacau.

42b. Bauhinia forficata subsp. pruinosa (Vogel) Fortunato \& Wunderlin, Darwiniana 27(1/4):550. 1986 [1987]. 三 Bauhinia pruinosa Vogel, Linnaea 13:301. 1839. $\equiv$ Pauletia pruinosa (Vogel) A. Schmitz, Bull. Jard. Bot. Nat. Belg. 43: 396. Tipo: BRASIL "Bras. merid.”, s.d. (fl./fr.), Sellow 2468 (holótipo B, destruído, fotografia RB! ex F negativo $\mathrm{n}^{\circ} 1607$ !).

= Bauhinia candicans Benth., in Mart., Fl. Bras. 15(2):201. 1870. $\equiv$ Pauletia candicans (Benth.) A.Schmitz, Bull. Jard. Nat. Belg. 43:389.1973. Tipo. "ad Missiones uruguayensis", s.d. (fl./fr.), Tweedie s.n. (lectótipo K, designado por Fortunato, 1986; fotografia A!, ex NY negativo $\mathrm{n}^{\circ}$ 1636).

Iconografia: Fortunato (1986 [1987]).

Árvores até $10 \mathrm{~m}$ alt. ou arvoretas $1-4 \mathrm{~m}$ alt. ou arbustos, com distribuição na Argentina, Paraguai e Uruguai, Bolívia (Fortunato 1986 [1987]) e Brasil, Estados do Paraná, Rio Grande do Sul, Santa Catarina e São Paulo (figura 3). Habita na floresta Atlântica, principalmente na faixa de clima subtropical, na orla da floresta, clareiras de capão com Araucária, campo, beira de estradas. Possui flores grandes e vistosas, com pétalas amplas obovadas, por esse motivo é cultivada como ornamental no Brasil.

43. Bauhinia integerrima Benth., in Mart., Fl. Bras. 15(2):197. 1870. Tipo: BRASIL: BAHIA: "ad Villa da Caxoeira", ano 1818 (fl.), Mart. Iter. Brasil. 2182 (holótipo M: fotografia RB! ex F negativo $\mathrm{n}^{\circ}$ 6221). = Bauhinia odoratissima Moric., Pl. Nouv. Am. 78 .
1840; non Newm. ex G. Don, 1832; 三 Pauletia odoratissima (Moric.) A. Schmitz, Bull. Jard. Bot. Nat. Belg. 43:395. 1973. Tipos: BRASIL: BAHIA: Nagé, s.d., Blanchet 2010 (síntipo não localizado); Ilhéus, s.d., Blanchet 2387 (isossíntipo OXF!, W!, A!, K: fotografia RB! ex NY negativo $n^{\circ} 1599$ ).

Iconografia: Moricand (1840, subnom. $B$. odoratissima).

Arbustos eretos ou escandentes, porém nunca com gavinhas, com distribuição no Brasil, na Bahia (figura 4). Habita na floresta Atlântica. B. integerrima é uma espécie endêmica da mata higrófila do sul da Bahia, ocorrendo também, em áreas de plantação de cacau.

44. Bauhinia mollis (Bong.) D. Dietr., Syn. Pl. 2:1475. 1840. $\equiv$ Pauletia mollis Bong., Mém. Acad. Imp. Sci. Saint-Pétersbourg, sér. 6, Sci. Math. seconde Pt. Sci. Nat. 4:133. 1838 (1836). Tipos: BRASIL: MAto Grosso: Cuiabá, s.d., G. Bongard 786 (síntipo LE); Camapuã, s.d., G. Bongard 620 (síntipo LE). Síntipos segundo Fortunato (1984).

= Bauhinia corumbensis S. Moore, Trans. Linn. Soc. London, Bot. 4(2):348. 1895. Tipo: BRASIL: MATO Grosso: Corumbá, s.d., S. Moore 1039 (holótipo NY!: fotografia $\mathrm{RB}$ !).

Iconografia: Fortunato (1984); Pott \& Pott (1994, fotografia).

Arvoretas 4-6 m de alt. ou arbustos 1-3 m alt., com distribuição na Bolívia, Paraguai (Fortunato 1984) e Brasil, Estados de Goiás, Mato Grosso e Mato Grosso do Sul, Minas Gerais e Tocantins. (figura 3). Em área do bioma Savana (sensu Joly et al. 1999), inclusive no complexo do Pantanal. Em formações de floresta semidecídua e decídua, cerradão, floresta de galeria, campo cerrado e cordilheiras. Também em áreas degradadas de beira de estrada e em lavouras. Segundo Pott \& Pott (1994) a freqüência aumenta com o desmatamento, rebrota após cortes ou fogo e indica solo fértil.

Bauhinia mollis é uma espécie distinta, isolada na série Aculeatae pela forma do botão floral, que tem o contorno clavado e apresenta constrição na região mediana dividindo o cálice em duas partes. Fortunato (1984) apresentou chave para distinguir Bauhinia mollis 
var. notophila (Griseb.) Fortunato, que ocorre no nordeste da Argentina e sul da Bolívia. No Brasil, há registro apenas para a variedade típica, que difere da variedade notophila por apresentar ovário velutino, cálice na antese com 5 lóbulos soldados e fenestrados na base ou fendidos em 2(3)lóbulos livres.

45. Bauhinia ovata (Bong.) Vogel, Linnaea 13:300. 1839. $\equiv$ Pauletia ovata Bong., Mém. Acad. Imp. Sci. Saint-Pétersbourg, sér. 6, Sci. Math. seconde Pt. Sci. Nat. 4:132. 1838 (1836). Tipo: "Hab. in Brasília" (holótipo não localizado).

Iconografia: Bongard (1836, sub nom. Pauletia ovata).

Arvoretas 5-6 m alt. ou arbustos, com distribuição no Brasil, Estados da Bahia, Espírito Santo e Minas Gerais (figura 5). Habita na floresta Atlântica, inclusive em formações floresta higrófila do sul da Bahia, nas plantações de cacau nesta área.

46. Bauhinia platypetala Burch. ex Benth., in Mart., Fl. Bras. 15(2):198. 1870. 三Bauhinia forficata var. platypetala (Burch. ex Benth.) Wunderlin, Ann. Missouri Bot. Gard. 60(2):571. 1973. 三 Pauletia platypetala (Burch. ex Benth.) A. Schmitz, Bull. Jard. Bot. Nat. Belg. 43:396. 1973. Tipos. BRASIL: Tocantins: Natividade, s.d., Gardner 3118 (síntipo OXF!); Conceição, s.d., Gardner 3700 (síntipo OXF!); Porto Nacional, s.d., (bt./fl.), Burchell Cat. Geogr. Pl. Bras. Tropicae 8563 (K: fotografia do síntipo RB!, ex NY negativo $\mathrm{n}^{\circ}$ 1602); MARANHÃo: s.d., Gardner 6009 (síntipo não localizado).

Iconografia: não há.

Arvoretas 4-10 m alt. ou arbustos 1,5-3 m alt., com distribuição na Bolívia e Brasil, Estados de Goiás, Maranhão, Mato Grosso, Pará, Piauí e Tocantins (figura 4). Habita na floresta Amazônica, zona dos Cocais e cerrado adjacente, floresta alta de terra firme com bastante cipó, floresta estacional, floresta alagada, contato cerrado/floresta estacional e, no Cerrado, em floresta de galeria e carrasco.

IV. Bauhinia ser. Ariaria (Cuervo-Marques) Wunderlin, K. Larsen \& S.S. Larsen, Biol. Skr. 28:13. 1987. $\equiv$ Ariaria Cuervo-Marques, Estud. Arq. Etno. Amer. 1:141. 1920. Tipo: Ariaria superba Cuervo-Marques [= Bauhinia tarapotensis Benth.].

Árvores ou arvoretas até arbustos escandentes lianóides. Ramos com acúleos ausentes. Nectários extraflorais cônico-ovóides, ápice truncado a obtuso, encaixados na parte cupulóide da estípula assimétrica, 1,8-3 × 1-1,2 mm. Folhas bilobadas, 9,5-19 × 7-15 cm. Pseudo-racemo terminal, em geral, com folhas de tamanho e forma normais nos nós proximais substituídas por brácteas foliáceas em direção ao ápice, inflorescências parciais com eixo bifurcado a bipartido, eixo, em geral, 0,5-1 cm compr., 2-floras, ou, às vezes, o botão gêmeo abortado; botão floral tubuloso-ensiforme, nunca alado, costado ou estriado, ápice exapendiculado, pré-antese ca. $13 \mathrm{~cm}$ compr.; hipanto reto, internamente tomentoso, cálice na antese subespatáceo, lobos unidos em direção ao ápice e amplamente fenestrado na base; pétalas linearlanceoladas, estreitando-se em direção à base ungüiculada, 10-12,5 ×0,9-1,3 cm, nunca lanosas externamente e na unha; 10 estames férteis, parcialmente conatos na base formando coluna irregular de 15-22 mm compr., coluna internamente pubescente, não bipartida, apêndice ligular ausente, externamente glabra, estaminódios ausentes; grãos de pólen 5-porados, com processos supratectais espinescentes (Ferguson \& Pearce 1986, Vaz 2001); estipe 5,5-7 cm, adnato em 1/4-1/2 do comprimento total do hipanto, estigma bilobado. Legume com contorno estreitamente oblanceolado, valvas $22-25 \times 2,5-3,8 \mathrm{~cm}$, internamente não divididas em compartimentos, externamente sem margem ventral elevada. Sementes não examinadas.

Distribuição: América tropical (Wunderlin et al. 1987). Brasil.

47. Bauhinia tarapotensis Benth., in Mart., Fl. Bras. 15(2):198. 1870. Tipo: PERU: SAN MARTIN: Tarapoto, XII-1855/I-1856, Spruce 4417 (holótipo K: fotografia RB! ex K, isótipos E!, GRAH!, NY!, OXF!, W!). = Bauhinia amplifolia Ducke, Bol. Técn. Inst. Agron. Norte. 2:16. 1944. Syn. nov. Tipo: BRASIL: Amazonas: Tabatinga, Rio Solimões, III-1944 (fl.), Ducke 1594 (lectótipo MG! aqui designado, isolectótipos RB!, R!, SI). PERU: IQUitos, VIII-1906 (fr.), Ducke Herb. Amaz. Musei Parensis 7552 (síntipo MG!, INPA!). Figura 2.

Iconografia adicional: não há.

Árvores 12-21 m alt., arvoretas de 4-7 m alt., trepadeiras ou lianas, porém nunca com gavinhas, com distribuição na Colômbia, Equador, Peru e Brasil, nos estados do Acre e Amazonas, região da fronteira com a Colômbia e o Peru, alto Solimões e alto Juruá (figura 5). Habita na floresta Amazônica, em formações de várzea e vegetação ao longo dos rios. Bauhinia tarapotensis foi considerada afim de B. breviloba (= B. forficata), 


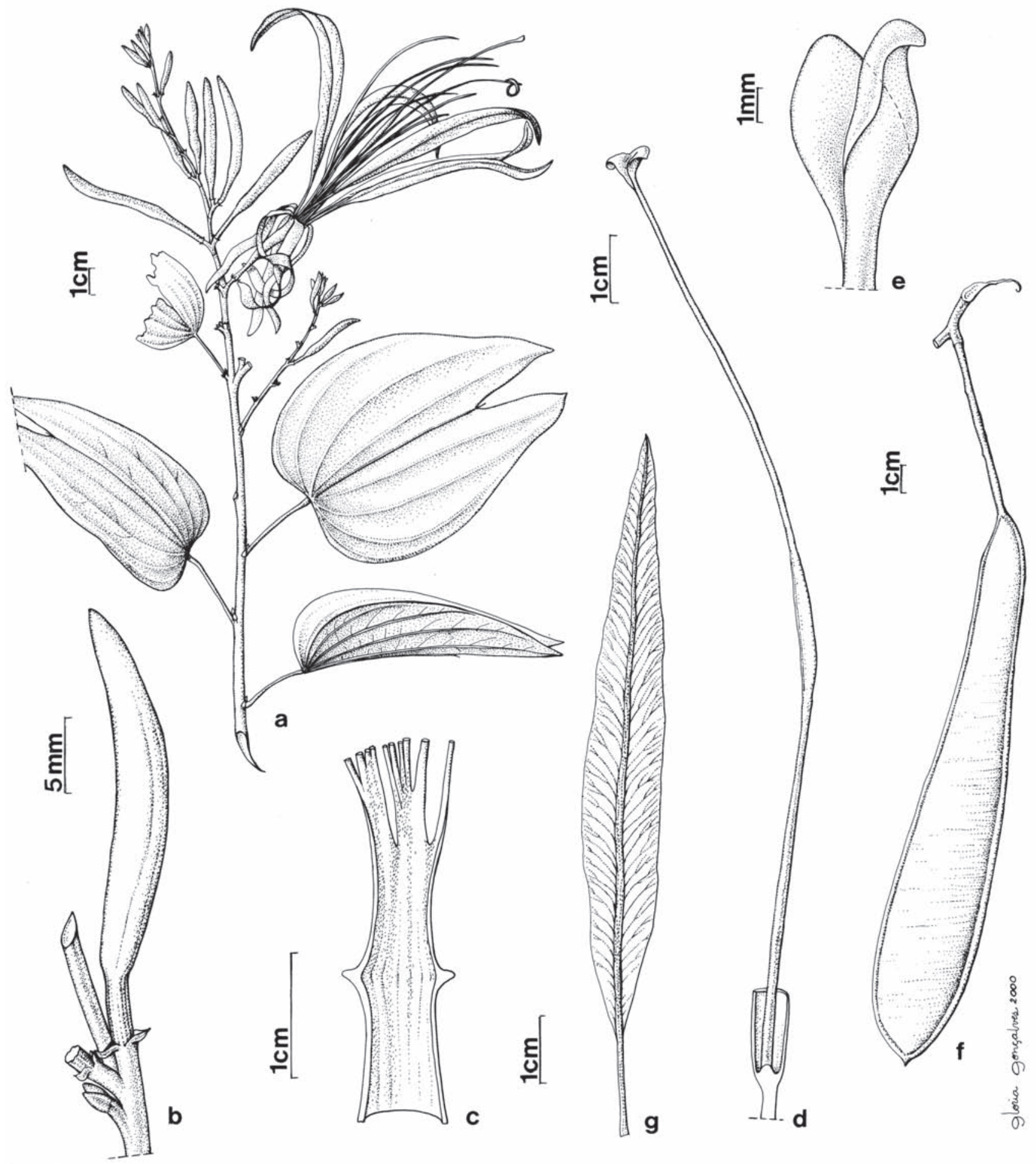

Figura 2. Bauhinia tarapotensis a. Ramo florífero com botões e flor com filetes porém, sem as anteras já caducas. b. Botão floral, observe o par de nectários extraflorais no eixo da inflorescência. c. Parte inferior dos filetes e coluna estaminal em continuidade com a face interna do hipanto. d. Gineceu inserido no hipanto seccionado. e. Detalhe do estigma bilobado. f. Legume. g. Uma das pétalas na antese (a-e, g: Daly 8633; f: Silveira 1287).

Figure 2. Bauhinia tarapotensis. a. Flowering branch with buds and flower with filaments but, without the caducous anthers. b. Floral bud, see the pairs of the extrafloral nectaries in the inflorescence axis. c. Inferior portion of the filaments and staminal column in continuity with the internal face of the hypanthium. d. Gynoecium included in the sectioned hypanthium. e. Detail of the bilobed stigma. f. Legume. g. One of the petals at anthesis (a-e, g: Daly 8633; f: Silveira 1287). 
por Bentham (1870), mas difere por ser inerme, apresentando nectários extraflorais e grãos de pólen 4-6-porados com processos supratectais espinescentes.

\section{Bauhinia ser. Pentandrae Wunderlin et al., Biol. Skr.} 28:13. 1987. Tipo: Bauhinia pentandra (Bong.) Steud.

Arvoretas até arbustos escandentes lianoides. Ramos com acúleos geminados, infra-estipulares, rígidos, aplanados, deltóides ou dilatado-uncinados em direção ao ápice retos ou recurvos, nunca incurvos, às vezes um dos acúleos é menor ou deficiente até ausente (acúleos solitários ou quase) até rudimentares em B. vespertilio. Nectários extraflorais ausentes. Folhas bilobadas a bifolioladas, às vezes concomitantemente bilobadas em $B$. corniculata, 3,9-9,2 × 3,8-10,8 cm. Inflorescências parciais, 2 -floras, eixo ausente a $0,4 \mathrm{~cm}$ compr., bipartido, bráctea foliácea ausente; botão floral clavado, alado ou corniculado até com cornículas obsoletas no ápice, nunca cristado, pré-antese $5-9,5 \mathrm{~cm}$ compr.; hipanto tubuloso, internamente vilosopubescente; cálice na antese fendido em 2-5 lobos parcialmente unidos no ápice ou livres, nunca espatáceo;

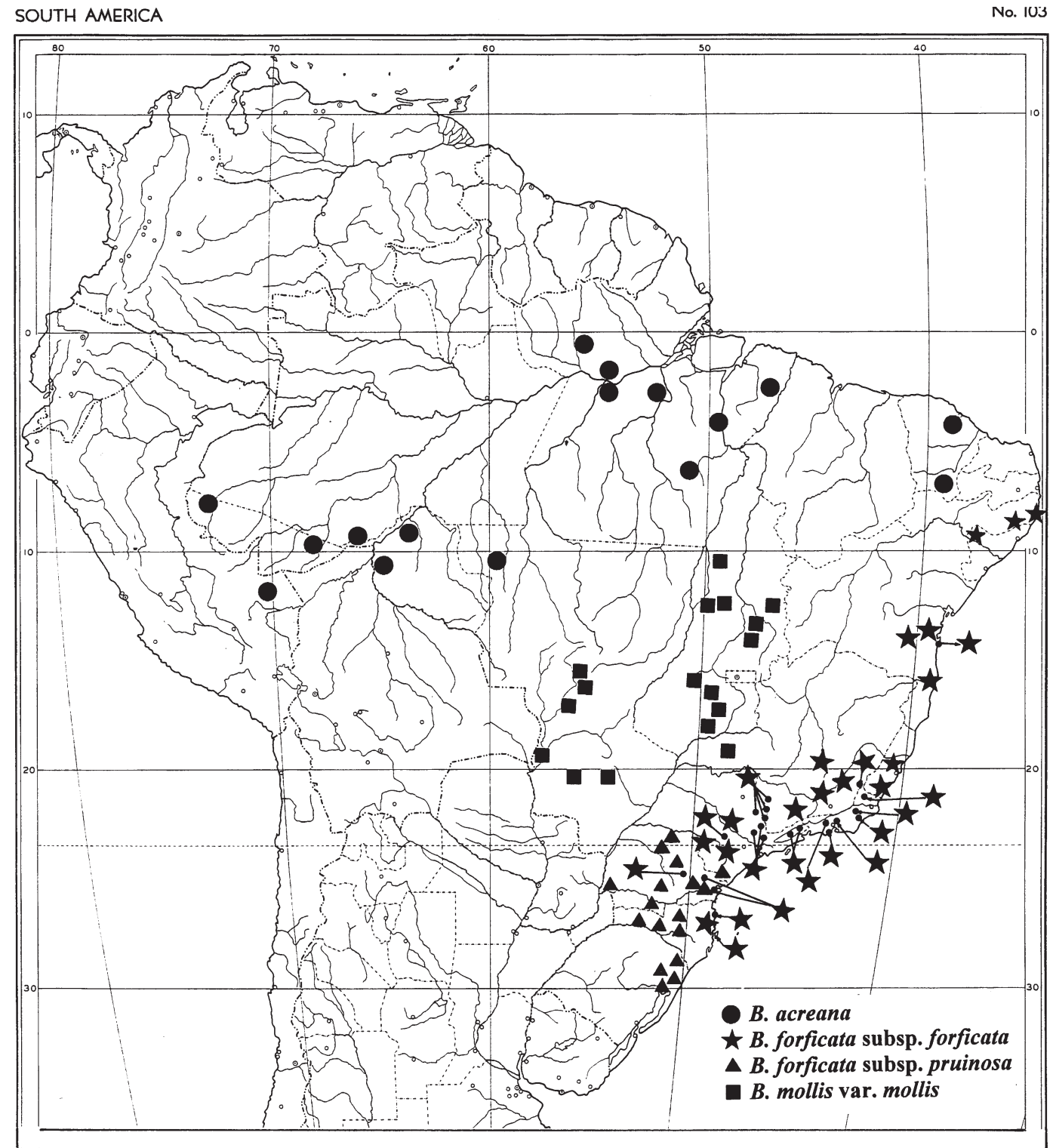

Figura 3. Mapa mostrando a distribuição geográfica de Bauhinia acreana, Bauhinia forficata e Bauhinia mollis no Brasil.

Figure 3. Map showing the geographical distribution of Bauhinia acreana, Bauhinia forficata and Bauhinia mollis in Brazil. 
pétalas lineares ou elítico-lanceoladas, unguiculadas, 2-3,4 × 0,2-0,8 cm, não lanosas externamente e na unha; 5 estames férteis alternados com 5 estaminódios filiformes ou com anteras vestigiais ou, ainda, alternados com 5 estames com anteras deficientes de até $2 \mathrm{~mm}$ compr., conatos na base formando coluna irregular de 5-7 mm compr., internamente diadelfa, com apêndice ligular obsoleto, viloso a viloso-hirsuto, externamente glabra; grãos de pólen 5-colpados, raramente 3-4-6 colpado, colpos longos e estreitos, muito profundos em vista polar, com processos supratectais gemóides; estipe 2-3,5 cm, livre, estigma assimetricamente clavado. Legume com contorno estreitamente oblongo, valvas $11-19,5 \times 1,2-2 \mathrm{~cm}$, internamente não divididas em compartimentos com câmaras que alojam as sementes, externamente sem margem ventral elevada; semente sem apêndice unciforme encobrindo o hilo, sem linhas em leque e não foveolada.

Distribuição: América tropical. Sete espécies na América do Sul até o México (Wunderlin et al. 1987).

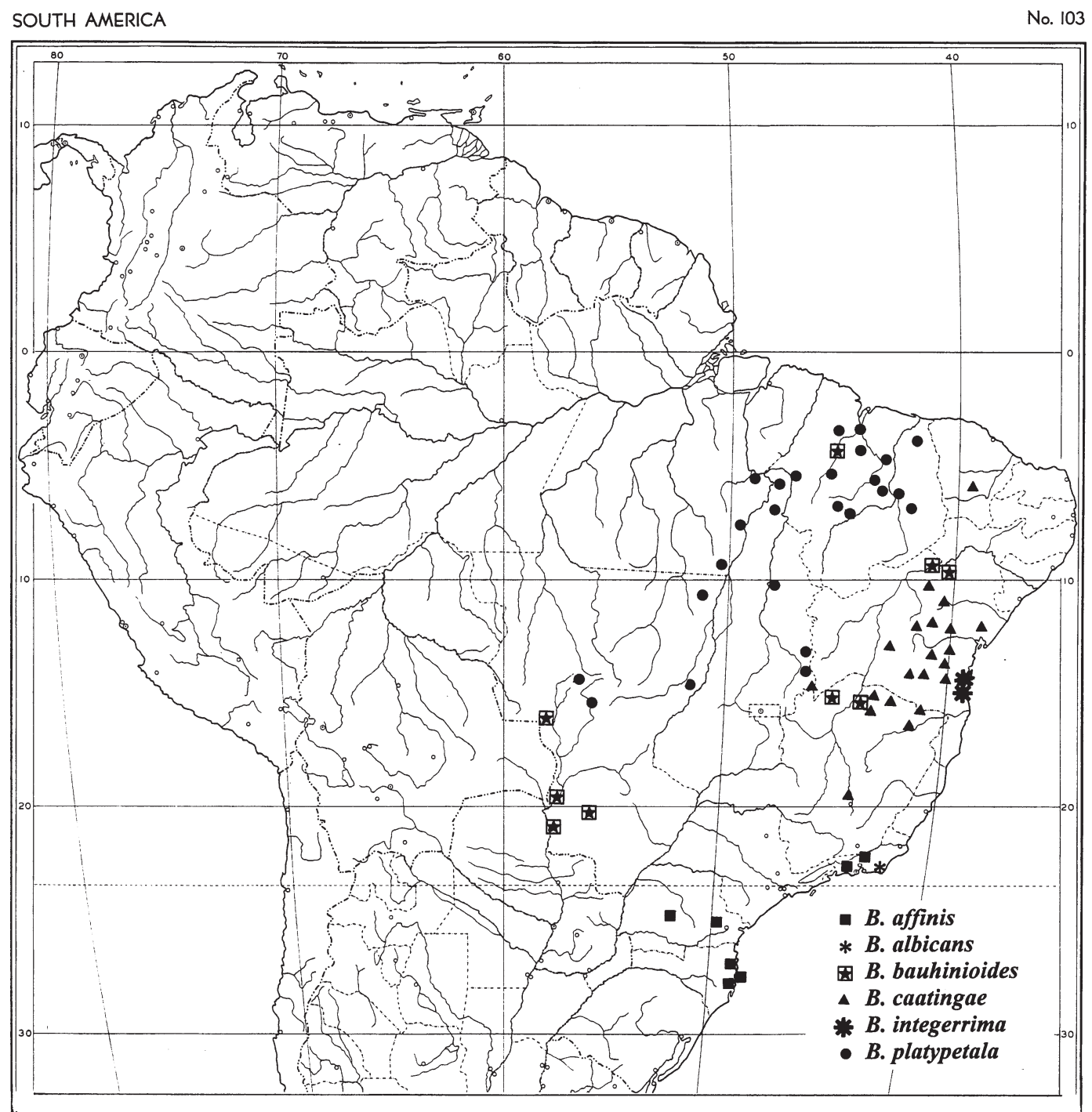

Figura 4. Mapa mostrando a distribuição geográfica de Bauhinia affinis, Bauhinia albicans, Bauhinia bauhinioides, Bauhinia caatingae, Bauhinia integerrima e Bauhinia platypetala no Brasil.

Figure 4. Map showing the geographical distribution of Bauhinia affinis, Bauhinia albicans, Bauhinia bauhinioides, Bauhinia caatingae, Bauhinia integerrima and Bauhinia platypetala in Brazil. 
Chave para as espécies de Bauhinia ser. Pentandrae no Brasil

1. Botão floral liso, 5-corniculado no ápice, cornículas divaricadas 48. B. corniculata

1. Botão floral 5-estriado a 5-alado, não corniculado

2. Ramos jovens e botões hirsutos a hirsuto-tomentosos 52. B. vespertilio

2. Ramos jovens e botões pubescentes

3. Pétalas elíticas a elítico-lanceoladas, 7-8 mm larg. 49. B. hagenbeckii

3. Pétalas lineares, $1 \mathrm{~mm}$ larg.

4. Lobos foliares largamente elíticos com nervura elevada nos bordos 50. B. marginata

4. Lobos foliares arqueado-divaricados sem nervura elevada nos bordos 51. B. pentandra

48. Bauhinia corniculata Benth., in Mart., Fl. Bras. 15(2):198. 1870. Tipo: BRASIL: PARÁ: Óbidos, s.d. (bt./fl./fr.), Spruce 497 (holótipo K: fotografia RB! ex F negativo 1573).

Iconografia: não há.

Arbustos ca. de 2-3 m alt., com distribuição na Bolívia, Colômbia, Peru e Brasil, nos Estados do Amazonas e Pará (figura 5). Habita na floresta Amazônica, em vegetação de várzea, ao longo dos rios Solimões e Amazonas.

Bentham (1870) incluiu esta espécie no terceiro grupo de espécies da seção Pauletia, correspondente a Bauhinia ser. Aculeatae. No entanto, pelo tipo de acúleo e botão floral, entre outros caracteres, $B$. corniculata enquadra-se melhor na série Pentandrae.

49. Bauhinia hagenbeckii Harms, Bot. Jahrb. Syst. 33(72):21. 1903. Tipo: BRASIL: “Gran Chaco", IV-1898 (fl.), Hagenbeck s.n. (holótipo B, destruído: fotografia RB! ex F negativo 1585; lectótipo fragmento F!, designado por Wunderlin 1968).

Iconografia: não há.

Arbustos, com distribuição no Paraguai e Brasil. O Brasil é citado no protólogo da espécie como localidade típica, mas até agora não foram encontrados outros espécimes desta espécie, ocorrendo no Brasil.

50. Bauhinia marginata (Bong.) Steud., Nom. Bot. ed. 2, 191 sphalm. 291. 1840 三 Pauletia marginata Bong., Mém. Acad. Imp. Sci. Saint-Pétersbourg, sér. 6, Sci. Math. seconde Pt. Sci. Nat. 4:121. 1838 (1836). Tipo: BRASIL: SÃo PAULO: "in campis siccis Rio Pardo", s.d., coletor não citado (holótipo não localizado).

Iconografia: Bongard (1838, folha).

Arbustos com distribuição no Brasil, Estados do Mato Grosso, Mato Grosso do Sul e São Paulo (figura 5). Habita no cerrado menos denso e no campo.

Bentham (1870) incluiu esta espécie no primeiro grupo informal da seção Pauletia, atual série Cansenia, mas esta espécie é afim de $B$. pentandra, e pertence à série Pentandrae, pelo tipo de inflorescência, botão floral e pela forma dos acúleos. Espécie raramente representada nas coleções.

51. Bauhinia pentandra (Bong.) D. Dietr. Syn. Pl. 1475. 1840 . $\equiv$ Pauletia pentandra Bong., Mém. Acad. Imp. Sci. Saint-Pétersbourg, sér. 6, Sci. Math. seconde Pt. Sci. Nat. 4:126. 1838 (1936). Tipo: BRASIL: Mato Grosso: "prope Cuyabá in montium jugo", coletor não citado (holótipo não localizado).

= Bauhinia heterandra Benth., in Mart., Fl. Bras. 15(2):196. 1870. Tipos: BRASIL: CEARÁ: Icó, VIII-1839 (bt./fr.), Gardner 1565 (lectótipo K, designado por Wunderlin in sched.: fotografia RB! ex NY negativo $\mathrm{n}^{\circ}$ 1597); B AHIA: Joazeiro, s.d., Martius s.n. (síntipo não localizado). Piauí: Boa Esperança, VII-1839 (fl./fr.), Gardner 2156 (síntipo K: fotografia. RB!, isossíntipo OXF!); GoIás: Goiás Velho, s.d., Burchell Cat. Pl. Brasilieae $n^{\circ} 73 A A$ (síntipo K: fotografia RB!); entre Funil e S. João, s.d., Burchell Cat. Pl. Brasilieae 8896 et 8868-2 (síntipo $\mathrm{K}$ : fotografia RB!).

Iconografia: Pott \& Pott (1994); Vaz (2003).

Arvoretas 4-5 m alt. ou arbustos 0,5-3,5 m alt. até arbustos escandentes, com distribuição na Bolívia e Brasil, Estados de Alagoas, Bahia, Ceará, Goiás, Minas Gerais, Mato Grosso, Mato Grosso do Sul, Paraíba, Pernambuco, Piauí, Rio de Janeiro, Rio Grande do Norte, São Paulo e Sergipe (figura 5). Habita nos biomas Caatinga e Savana. Na região nordeste ocorre na caatinga, transição caatinga/cerrado e floresta estacional. Na região centro-oeste ocorre em cerradão, mata de galeria e floresta seca. Em Minas Gerais, há uma ocorrência no domínio de caatinga (rio Verde Grande) e outra no cerrado (Tupaciguara). No Estado do Rio de Janeiro, há uma coleção de Cabo Frio [VI-1941, N. Santos \& de Lauro s.n., (R)], cuja ocorrência configura uma área disjunta da espécie. Em 
São Paulo, só é encontrada na área de cerrado na fronteira com Mato Grosso do Sul. Há dois indivíduos em cultivo no canteiro 1E do Jardim Botânico do Rio de Janeiro. Um deles, após atingir porte de arvoreta apoiou-se na copa de uma árvore mais próxima, adquirindo hábito lianóide.

Bentham (1870) reconheceu $B$. pentandra e $B$. heterandra como espécies distintas. As principais diferenças apontadas na chave de identificação foram: estaminódios filiformes e botões 5-costados em $B$. pentandra e filetes alternos com anteras pequenas, ca. $4 \mathrm{~mm}$ compr. e botões 5-alados em $B$. heterandra. A área de distribuição de $B$. pentandra incluiu o Estado do Mato Grosso e o Paraguai e a área de B. heterandra foi basicamente o nordeste, com um ponto em Goiás. Com o aumento das coleções verificou-se que foram coletados espécimes com estaminódios que possuem anteras vestigiais na Baia Flores e Anastácio em Mato Grosso. Botões alados também ocorrem em coleções do Mato Grosso. Diante disso, a circunscrição de $B$. pentandra é aqui ampliada, incluindo $B$. heterandra.

52. Bauhinia vespertilio S. Moore, Trans. Linn. Soc. ser 2, 4:347. 1895. Tipo: BRASIL: Mato Grosso: Santa Cruz, 1891/1892, S. Moore iter matogrossense 587

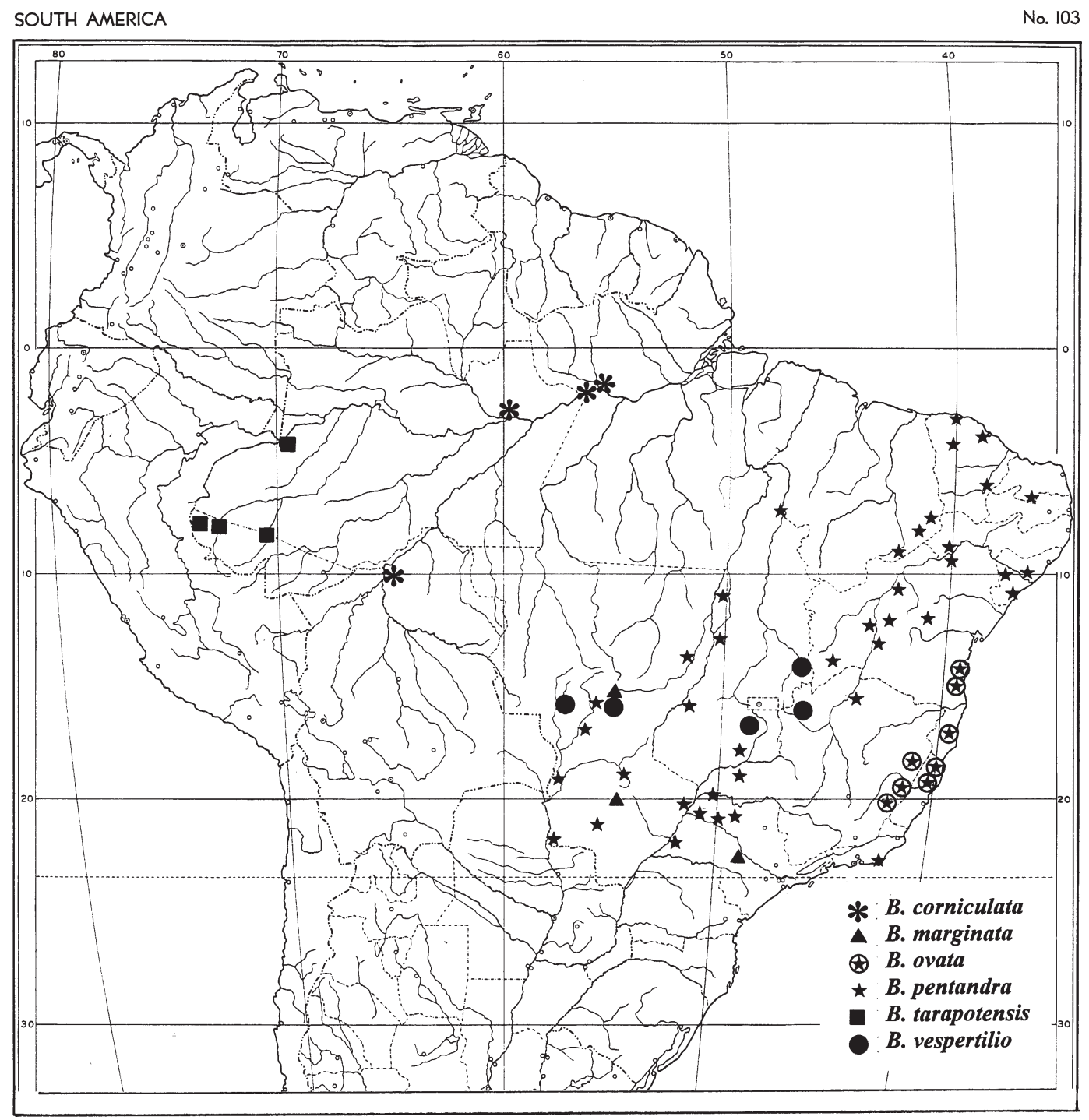

Figura 5. Mapa mostrando a distribuição geográfica de Bauhinia corniculata, Bauhinia marginata, Bauhinia ovata, Bauhinia pentandra, Bauhinia tarapotensis e Bauhinia vespertilio no Brasil.

Figure 5. Map showing the geographical distribution of Bauhinia corniculata, Bauhinia marginata, Bauhinia ovata, Bauhinia pentandra, Bauhinia tarapotensis and Bauhinia vespertilio in Brazil. 
(holótipo BM, isótipo NY!: fotografia RB! ex NY negativo ${ }^{\circ} 12713$ ).

$=$ Pauletia hirsuta Bong., Mém. Acad. Imp. Sci. SaintPétersbourg, sér. 6, Sci. Math. seconde Pt. Sci. Nat. 4:134. 1838 (1836); 三Bauhinia hirsuta (Bong.) Vogel, Linnaea 13:300. 1839 (non Weinm., 1828); 三Bauhinia hirsutiflora Vaz, Atas Soc. Bot. Brasil sec. Rio de Janeiro 3(20):3. 1995. Syn. nov. Tipo. BRASIL: Mato Grosso: Cuiabá, II-1827 (bt.), Riedel 825 (holótipo LE: fotografia RB! ex F negativo 1588).

Iconografia: Bongard (1836, subnom. P. hirsuta); Vaz (2003, subnom. B. hirsutiflora).

Arvoretas ca. $3 \mathrm{~m}$ de alt. ou arbustos ca. $2 \mathrm{~m}$ de alt., com distribuição no Brasil, Estados de Goiás, Maranhão e Mato Grosso (figura 5). Habita no bioma Savana (sensu Joly et al. 1999), na floresta de encosta, orla de floresta com cerrado, cerrado e campo cerrado muito denso. Bauhinia vespertilio apresenta acúleos reduzidos e caducos, imperceptíveis a olho nu, porém sensíveis ao tato.

VI. Bauhinia ser. Perlebia (Mart.) Wunderlin, K. Larsen \& S.S. Larsen, Biol. Skr. 28:13. 1987. Tipo: Perlebia bauhinioides Mart. $[=$ Bauhinia bauhinioides (Mart.) J.F. Macbr.]

Arvoretas até arbustos escandentes lianóides. Ramos com acúleos geminados, infra-estipulares, rígidos, aplanado-subulados, retos ou incurvos em direção ao ápice, nunca recurvos, raramente um dos acúleos é menor ou deficiente até ausente (acúleos solitários ou quase). Nectários extraflorais ausentes. Folhas bifolioladas, folíolos em geral 1,2-2,5 ×1,1-2 cm. Inflorescências parciais, 2-floras, eixo $0,5 \mathrm{~cm}$, bipartido, bráctea foliácea ausente; botão floral clavado, nunca alado ou costado, com apêndices rudimentares no ápice, pré-antese 4-5,5 cm compr.; hipanto tubuloso, internamente glabro; cálice na antese espatáceo e fenestrado em mais da metade do comprimento; pétalas lineares, ungüiculadas, 1,7-3,2 ×0,1 cm, lanosas externamente e na unha; 5 estames férteis alternados com 5 estaminódios filiformes, conatos na base formando coluna irregular até $10 \mathrm{~mm}$ de altura, internamente diadelfa, com apêndice ligular obsoleto, viloso, externamente vilosa a pubescente; grãos de pólen 5-colpados, 3-4- ou 6-colpados, colpos longos e estreitos, muito profundos em vista polar, com processos supratectais gemóides (Gamerro \& Fortunato 1999, Vaz, 2001); estipe $2 \mathrm{~cm}$ compr., livre, estigma assimetricamente clavado. Legume indeiscente, raro tardiamente deiscente (Fortunato 1986 [1987]), estreitamente oblongo a levemente falciforme, valvas 7-14,5 × 1,5-1,9 cm, internamente divididas em compartimentos com câmaras que alojam as sementes, externamente sem margem ventral elevada; semente sem apêndice unciforme encobrindo o hilo, sem linhas em leque e não foveolada.

Distribuição: Cuba, Brasil, Paraguai e Argentina.

53. Bauhinia bauhinioides (Mart.) J.F. Macbr., Contrib. Gray Herb. n. ser. 59:22. 1919. $\equiv$ Perlebia bauhinioides Mart. ex Spix \& Mart., Reise Bras. ed.1, vol 2:555. 1823. $\equiv$ Pauletia bauhinioides (Mart.) Schmitz, Bull. Jard. Bot. Nat. belgique 43:388. 1973. Tipo: BRASIL: MinAS GERAIs: Alagadisso, San Francisco, Martius s.n. (síntipos M, fotografias BAB, fide Fortunato 1986 [1987]).

= Bauhinia microphylla Vogel, Linnaea 15(2):301. 1839. Tipo: BRASIL, "ad Faz. da Piedade", s.d. (fr.), Sellow 950 (holótipo B, destruído: fotografia RB! ex F negativo 1596).

Iconografia: Fortunato (1986 [1987]), Pott \& Pott (1994).

Arvoretas bem ramosas, arbustos 2-3 m de alt. ou arbustos escandentes a lianas (L.Queiroz \& N.S. Nascimento 3919, HUEFS), com distribuição Argentina e Paraguai (Fortunato 1986 [1987]), Cuba e Brasil, Estados da Bahia, Maranhão, Minas Gerais, Mato Grosso do Sul e Piauí (figura 4). Habita na Caatinga e no pantanal, em mata ciliar, caatinga inundável, em locais alagados ou periodicamente inundáveis, margens de lagoa, campos úmidos. Invasora de pastagens e colonizadora de beira de estrada, rebrota após cortes e fogo, diminuindo com a queimada (Pott \& Pott 1994). No pantanal, tem o nome popular de "espinho-do-diabo" e, muitas vezes, está associada a outros espinheiros, como Byttneria filipes Mart. e Mimosa sp. (Pott \& Pott 1994).

Agradecimentos - Ao Instituto de Pesquisas Jardim Botânico do Rio de Janeiro e ao Departamento de Botânica da Unicamp, pelo uso de equipamentos e dependências; aos curadores dos herbários pelo atendimento, empréstimo e/ou doação de espécimes e fotografias de tipos, em especial à curadoria dos Herbários RB e UEC, pelo apoio nas solicitações de empréstimo e devolução de exsicatas; ao Dr. Scott Mori e Dr. Gwillym Lewis, pelas facilidades durante visita aos Herbários NY e K, respectivamente; ao Herbário K, pela doação de cibacromos; às equipes dos herbários Cepec, na pessoa do Prof. André A. Amorim, IBGE, em especial à Profa. Roberta Mendonça, e UFG, na pessoa da Profa. Vera Lúcia G. Klein, pela apoio nas atividades em campo; à Dra. Mônica Barth, do laboratório de Palinologia do Centro de Ciências da Saúde, UFRJ, pelos ensinamentos e pelo uso do laboratório para o 
estudo do pólen; à Profa. Andrea Luizi-Ponzo, pelo acompanhamento e pela assistência no estudo palinológico; à Dra Maria do Carmo Mendes Marques, pela cuidadosa revisão do texto e pelas sugestões; à Eng. Agrônoma Renée Fortunato pelo envio de cópias de publicações e de tipos e também pelas valiosas sugestões no texto final; ao Prof. Ronaldo Marquete, IBGE/Derna/Diren, pelo auxílio na confecção dos mapas; ao CNPq pela bolsa de doutorado concedida ao primeiro autor.

\section{Referências bibliográficas}

BELTRATI, C.M. \& PAOLI, A.A.S. 1989. Morfologia, anatomia e desenvolvimento das sementes e plântulas de Bauhinia forficata Link. (LeguminosaeCaesalpinioideae). Revista Brasileira de Biologia 49:583-590.

BENTHAM, G. 1870. Leguminosae II. Swartzieae et Caesalpinieae. In Flora Brasiliensis (C.P.F. Martius \& A.G. Eichler, eds.). F. Fleisher, Lipsiae v.15, pars 2, p.179 212.

BONGARD, A.G.H. 1838 (1836). Bauhinia et Pauletiae species brasiliensis novae. Mémoires de l'Académie Imperiale des Sciences de Saint-Petersbourg 4:109-136.

DE WIT, H.C.D. 1956. A revision of Malaysian Bauhinieae. Reinwardtia 3:381-539.

DUCKE, A. 1922. Leguminosae in Plantes nouvelles ou peu connues de la region amazonienne II. Arquivos do Jardim Botânico do Rio de Janeiro 3:3-285.

DUCKE, A. 1949 (1950). As Leguminosas da Amazônia Brasileira. Boletim Técnico Instituto Agronômico do Norte 18:1-248.

FERGUSON, I.K. \& PEARCE, K.J. 1986. Observations on the pollen morphology of the genus Bauhinia L. (Leguminosae: Caesalpinioideae) in the neotropics. In Pollen and Spores: Form and function (S. Blackmore \& I.K. Ferguson, eds.). Academic Press, London, p.283-296.

FORTUNATO, R.H. 1984. Nota crítica sobre Bauhinia mollis (Bong.) D. Dietr. (Caesalpinioideae Leguminosae). Parodiana 3:43-52.

FORTUNATO, R.H. 1986 [1987]. Revision del genero Bauhinia (Cercideae, Caesalpinioideae, Fabaceae) para la Argentina. Darwiniana 27:527-557.

FORTUNATO, R.H. 1996. Bauhinia affinis (Fabaceae) uma nueva cita para la flora Argentina. Darwiniana 34:405-409.

GAMERRO, J.C. \& FORTUNATO, R.H. 2001. Morfologia del polen de las especies argentinas de Bauhinia (Cercideae, Caesalpinioideae, Fabaceae). Annals of the Missouri Botanical Garden 88:144-158.

HOLMGREN,P.K., HOLMGREN, N.H. \& BARNETT,L.C. 1990. Index Herbariorum, part 1. The Herbaria of the World. ed. 8. Regnum Vegetabile v.120. New York Botanical Garden, New York.
JOLY, C.A., AIDAR, M.P.M., KLINK, C.A., MCGRATH, D.G., MOREIRA, A.G., MOUTINHO, P., NEPSTAD, D.C., OLIVEIRA, A.A., POTT, A., RODAL, M.J.N. \& SAMPAIO, E.V.S.B. 1999. Evolution of the Brazilian phytogeography classification systems: implications for biodiversity conservation. Ciência e Cultura 51:331-348.

GREUTER, W. (coord.) 2000. International Code of Botanical Nomenclature. (Saint Louis Code). Koeltz Scientific Books. Konigstein. Tradução de C.E.M. Bicudo \& J. Prado. São Paulo.

LARSEN, S.S. 1975. Pollen morphology of Thai species of Bauhinia. Grana 14:114-131.

LIMA, H.C. 1995. Leguminosas da Flora Fluminensis - J.M. da C. Vellozo - Lista atualizada das espécies arbóreas. Acta Botanica Brasilica 9:123-146.

LORENZI, H. 1992. Árvores brasileiras. Manual de identificação, Editora Plantarum Ltda, Nova Odessa.

MORICAND, S. 1840. Plantes Nouvelles d'Amerique. Genève, v.6. Imprimerie de Jules-Gme Fick.

POTT, A. \& POTT, V.J. 1994. Plantas do Pantanal. Embrapa, Centro de Pesquisa Agropecuária do Pantanal. Corumbá.

TRIVEDI, B.S., BAGCHI D, G. \& BAJPAI, U. 1980. Studies on seeds and spermoderm structure of Bauhinia. Phytomorphology 30:11-16.

VAZ, A.M.S.F. 1979. Considerações sobre a taxonomia do gênero Bauhinia L. sect. Tylotaea (Leguminosae Caesalpinioideae) do Brasil. Rodriguesia 31:127-234.

VAZ, A.M.S.F. 2001. Taxonomia de Bauhinia sect. Pauletia (Leguminosae: Caesalpinioideae: Cercideae) no Brasil. Tese de doutorado, Universidade Estadual de Campinas, Campinas.

VAZ, A.M.S.F. 2003. Leguminosae Caesalpinioideae: Cercideae: Bauhinia. In Flora dos estados de Goiás e Tocantins. Coleção Rizzo. (J.A. Rizzo coord.). Goiânia, v.30, p.1-121.

VAZ, A.M.S.F. \& SILVA, D.C.P. 1995. Bauhinia (Leguminosae - Caesalpinioideae) da Reserva Florestal da Vista Chinesa, Rio de Janeiro. Albertoa 4:53-59.

VAZ, A.M.S.F. \& TOZZI, A.M.G.A. 2003a. Aculeatae, a new series in Bauhinia section Pauletia (Leguminosae, Caesalpinioideae, Cercideae). Novon 13:141-144.

VAZ, A.M.S.F. \& TOZZI, A.M.G.A. 2003b. Bauhinia ser. Cansenia (Leguminosae: Caesalpinioideae no Brasil). Rodriguésia 54:55-143.

WUNDERLIN, R.P. 1968. A note on Bauhinia hagenbeckii Harms. Phytologia 17: 245.

WUNDERLIN, R.P. 1976. The panamanian species of Bauhinia (Leguminosae). Annals of the Missouri Botanical Garden 63:346-354.

WUNDERLIN, R.P., LARSEN, K. \& LARSEN, S.S. 1981. Cercideae Bronn. In Advances in Legume Systematics (R.M. Polhill \& P.H. Raven, eds.). v.1, p.107-116.

WUNDERLIN, R.P., LARSEN, K. \& LARSEN, S.S. 1987. Reorganization of the Cercideae (Fabaceae: Casalpinioideae). Det Kongelige Danske Videnskabernes Selskab Biologiske Skrifter 28:1-40. 